\title{
Effect of Doll Injection Display on Pain Intensity due to Intramuscular Injection in Preschool Children
}

\author{
Irani H. ${ }^{1}$ MSc, Eshghizadeh M.1 ${ }^{M S c}$, Zivari M.* BSc
}

*Nursing Department, Nursing \& Midwifery School, Gonabad University of Medical Sciences, Gonabad, Iran 1Nursing Department, Nursing \& Midwifery School, Gonabad University of Medical Sciences, Gonabad, Iran

\begin{abstract}
Aims: Pains caused by the invasive actions such as intramuscular injection lead to the physical and mental tensions in the children. Therefore, such pains should be given relief. One of the main priorities in the nursing is to notice methods that reduce pains due to the invasive actions in the children. The aim of this study was to investigate the effects of injection displayed on a doll on the pain intensity due to the intramuscular injection in the preschool children.

Materials \& Methods: In the randomized controlled clinical trial, 62 kids aged between 4 and 6 years with pharyngitis were studied in the clinic of the health network of Khalil-abad Township in 2015. The intramuscular injection of penicillin 6.3.3 was administrated for the kids. The subjects, selected by simple lottery, were divided into two groups including experimental and control groups ( $\mathrm{n}=31$ per group). Data was collected using a demographic characteristic collecting form and Oucher standard pain assessment tool. In experimental group, the kid watching, one intramuscular injection was displayed on a doll by a nurse; then, the kid underwent an intramuscular injection. In control group, the routine injection method was done. Data was analyzed by SPSS 19 software using Mann-Whitney, independent T, and Chisquare tests.

Findings: Mean pain intensity after injection in experimental group $(3.22 \pm 0.90)$ was significantly lower than control group $(4.19 \pm 0.83 ; p<0.001)$.

Conclusion: The injection displayed on a doll before the intramuscular injection might lead to pain reduction in the preschool kids.
\end{abstract}

\section{Keywords}

Pain [http://www.ncbi.nlm.nih.gov/mesh/68010146];

Injections, Intramuscular [http://www.ncbi.nlm.nih.gov/mesh/68007273];

Doll [Not in MeSH];

Child, Preschool [http://www.ncbi.nlm.nih.gov/mesh/68002675]

\footnotetext{
*Corresponding Author

Tel: +985157727310

Fax: +985157727315

Address: Nursing \& Midwifery School, Gonabad University of Medical Sciences, Imam Khomeyni Street, Gonabad, Iran 
تنشزا و ترسناك در كودكان است. تزريقات به هر شكلى آزاردهنده

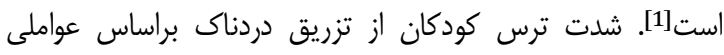

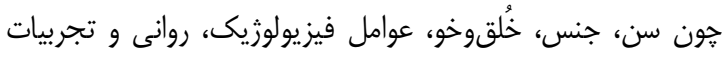
قبلى افراد در رويههاى مختلف، متفاوت است [2]. كودكان اغلب از

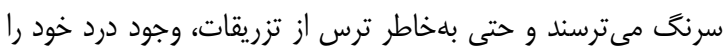

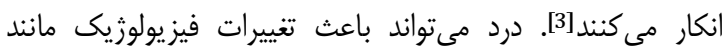
افزايش تعداد ضربان قلب و تنفس، تعريق، قرمزى يوست، كاهش

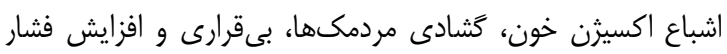
خون شود[4]. براى تسكين درد كودكان روشهاى مخدان مختلفى وجود

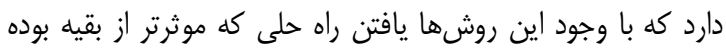



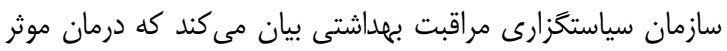

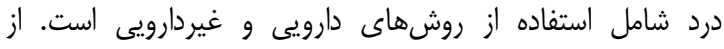

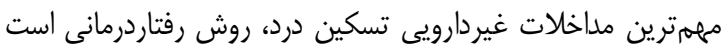

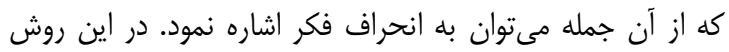

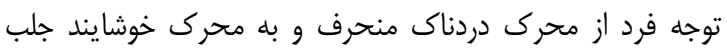



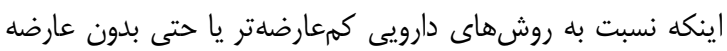

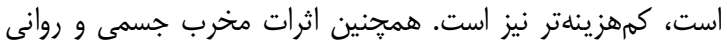

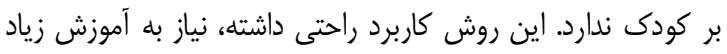

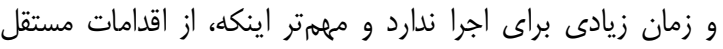



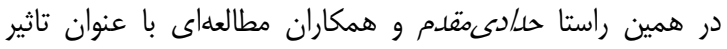



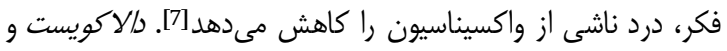

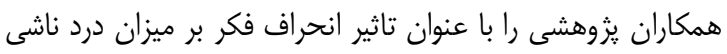

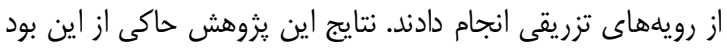

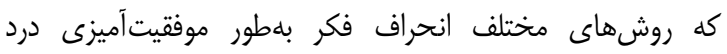

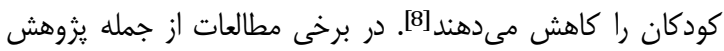
حسنيور و همكاران كه با هدف مقايسه انحراف فكر و سر سرمادرمانى انجام شد، نشان داده شده است كه هر دو روش دران در كاهش درد درد ناشى از تزريق موثر هستند دون]. روشهاى انحراف فكر شامل انحراف فكر بينايى (شمردن اشيا، تماشاى تلويزيون)، انحراف فكر شنيدارى (كوشدادن بحرن به موسيقى)،

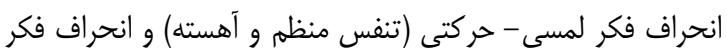

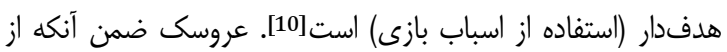

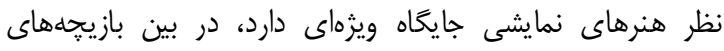

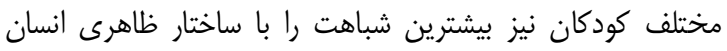

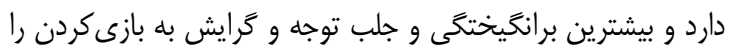

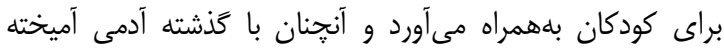

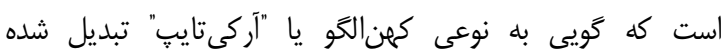

است][11]. - است

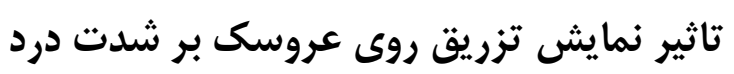

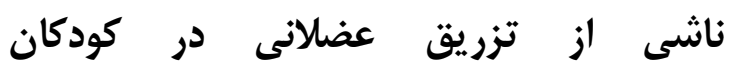
بيثىدبستانى ليشى

حسن ايرانى MSc

كروه يرستارى، دانشكده يرستارى و مامايى، دانشكاه علوم يزشكى كناباد، كَاباد،

ايران

MSc مريم عشقىز ايران

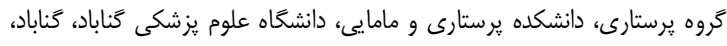

ايران

BSc مصطفى زيورى

كروه يرستارى، دانشكده يرستارى و مامايى، دانشخاه علوم يزشكى گناباد، كناباد، ايران

קكيده

اهداف: درد ناشى از اقدامات تهاجمى مثل تزريق عضلانى باعث

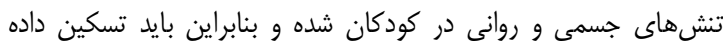

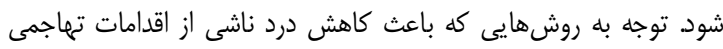

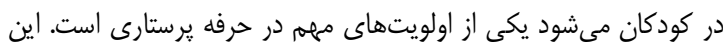

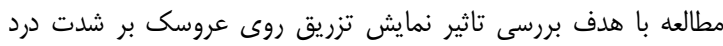

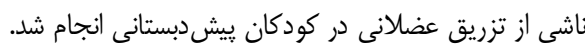

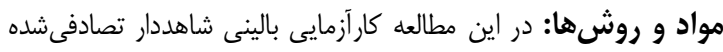

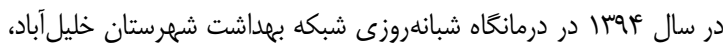

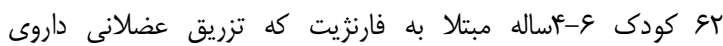

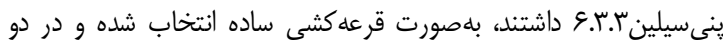

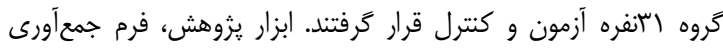

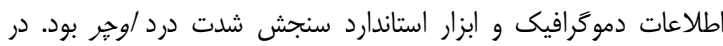

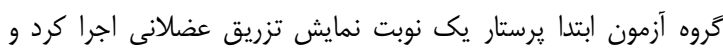

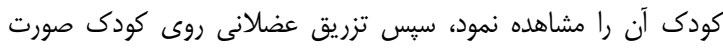

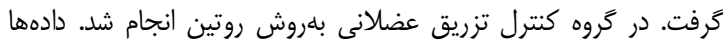

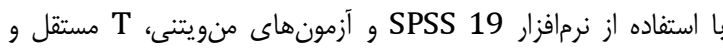
مجذور كاى مورد تجزيه و تحليل قرار گرفتند.

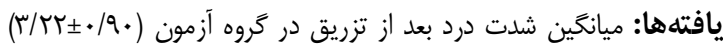

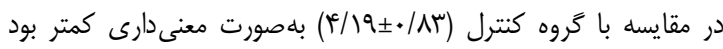

.$(\mathrm{p}<\cdot / \cdot+1)$

نتيجهَّيرى: نمايش تزريق روى عروسى قبل از تزريق عضلانى

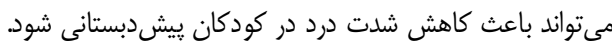

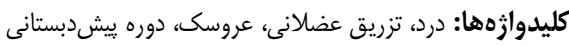

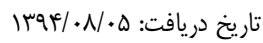

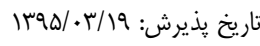

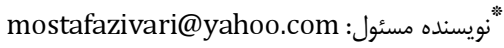

مقدمه درد ناشى از رويههاى درمانى و تزريقات يكى از شايعترين تجربيات



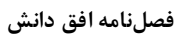




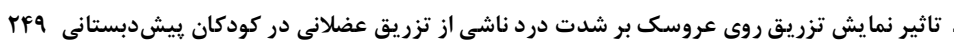

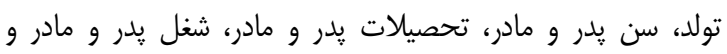

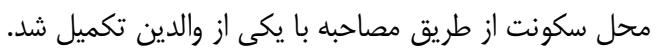

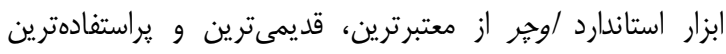

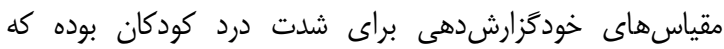

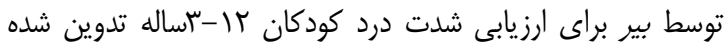

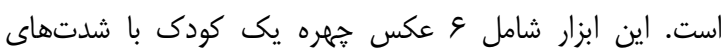

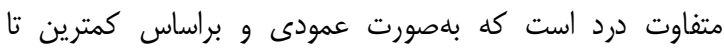

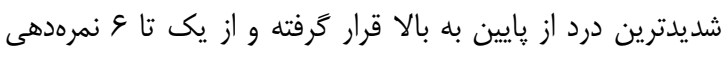

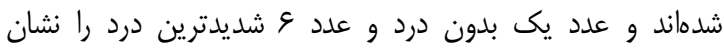
مىدهد. روايى و يايايى اين مقياس در مطالعات متعددى تاييد شده

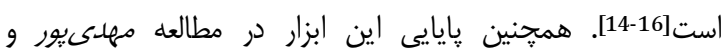

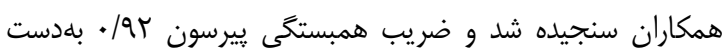

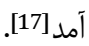

در گروه آزمون ابتدا يرستار يك نوبت نمايش تزريق عضلانى با

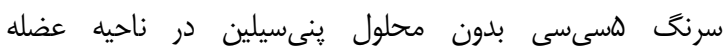

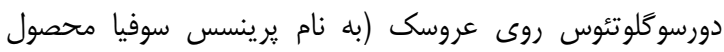
Jakks Pacific

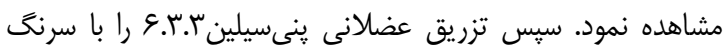
هسىسى و سرسوزن شماره זr روى كودى انجام داد. در گروه

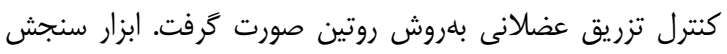

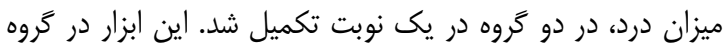

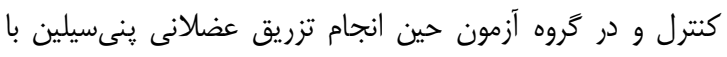
مشاهده جهره كودك تكميل شد.

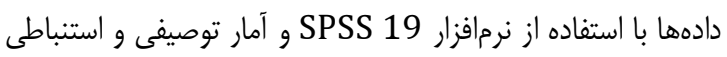
مورد تجزيه و تحليل قرار گرفتند. آزمون منويتنى براى مقايسه

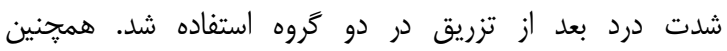
آزمونهاى T مستقل و مجذور كاى براى بررسى توزيع فراوانى متغيرهاى دموكرافيك در دو گروه آزمون و كنترل مورد استفاده قرار كرفتند.

\section{يافتهها}

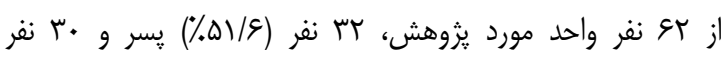

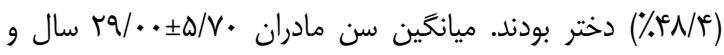

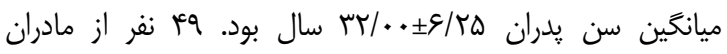

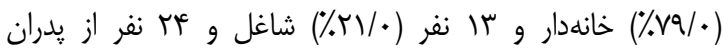
كارمند و ^ץ/V) ( )

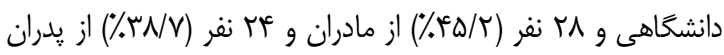
تحصيلات زير دييلهم داشتند. از نظر رتبه تولد بيشترين تعداد با فراوانى • ن نفر (س/rس\%) مربوط به رتبه اول (فرزند اول) و كمترين

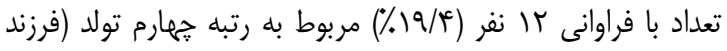
جهارم) بود. دو گروه از لحاظ سن و جنسيت كودى، سن يدر و
از ديدكاه بهداشت روان عروسكدرمانى شيوه دليذير مداوا در قلمرو

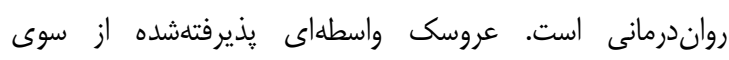
بزرگسالان و كودكان در جهت ارتباط و تبادل احساس، عاطفه و وروني

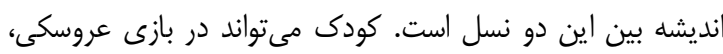

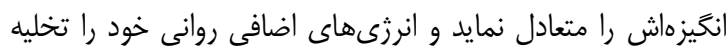

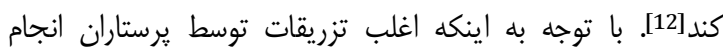
مىشود، اين گروه علاوه بر انجام دقيق و صحيح اين رويه

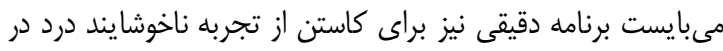
كودكان داشته باشند [13]. براساس توضيحات فوق مطالعاتى در مورد روشهاى مختلف فانف انحراف فكر و تاثير مثبت آن بر درد كودكان انجام شده است. ولى مونى از آنجا كه روش تزريق روى عروسك، يك روش سريع، كمهزينه و

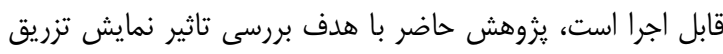
روى عروسك بر شدت درد ناشى از تزريق عضلانى در كودكان

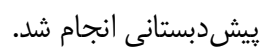

\section{مواد و روشها}

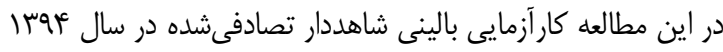

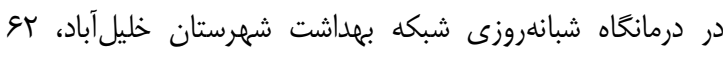
كودى و-أساله مبتلا به فارنزيت كه تزريق عضلانى داروى

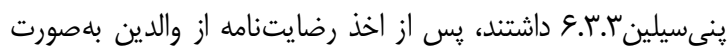
قرعه كشى ساده انتخاب شده و در دو گروه آزمون و كنترل قرار

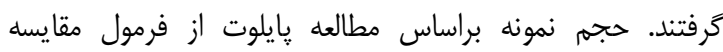

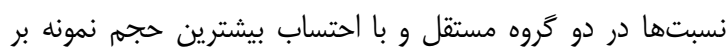

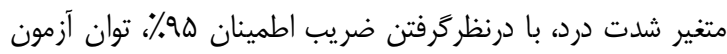

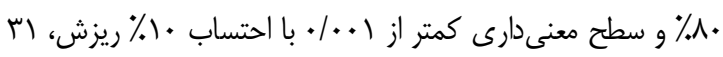

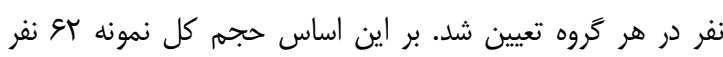

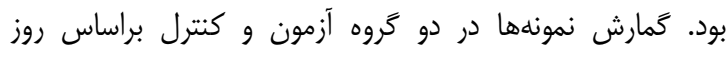

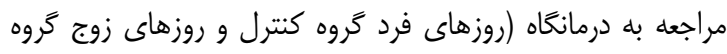


والدين، عدم تزريق عضلانى در يك هفته كذشته، عدم درد حاد و

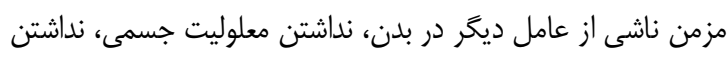

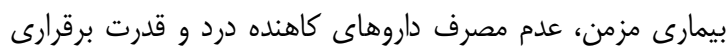
ارتباط بود. كودكانى كه با درمانگر همكارى نداشتند از مطالعه خارج

شدند. بعد از تاييد طرح توسط معاونت يزوهشى و كسب مجوز لازم از



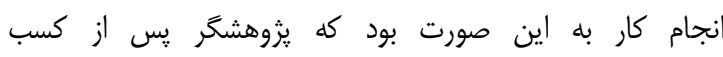
اجازهنامههاى لازم، در مركز بهداشتى درمانى شهرستان خليلآباد حضور يافت و اقدام بله نمونه گيرى نمود. ابزار يثوهش، فرم جمع آورى اطلاعات دموگرافيك و ابزار استاندارد

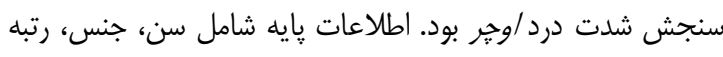


روش در كاهش درد ناشى از تزريق عضلانى موثر است. بنابراين

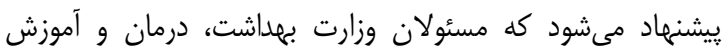

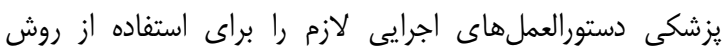

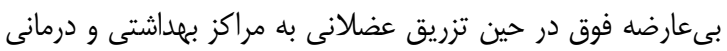

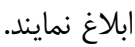

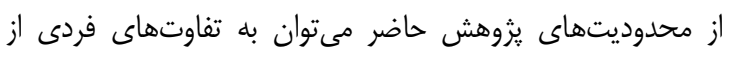

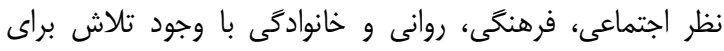

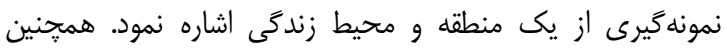

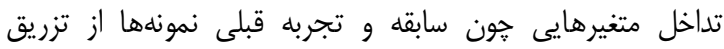

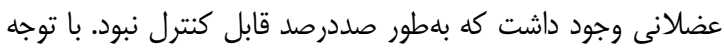
به تحقيق انجامشده، ييشنهاد مىشود تاثير روش نمايش تزريق

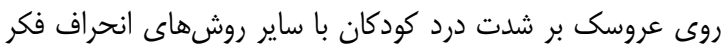

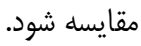

\section{نتيجلكيرى}

نمايش تزريق روى عروسك قبل از تزريق عضلانى مىتواند باعث كاهش شدت درد در كودكان ييشدبستانى شود.

تشكر و قدردانى: نويسندكان مقاله مراتب قدردانى و سباس

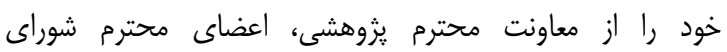

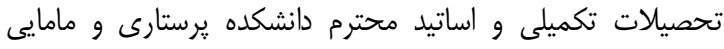

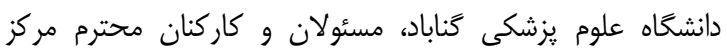
بهداشتى و درمانى شهرستان خليلآباد و كليه والدين و كودكان الدان إنان

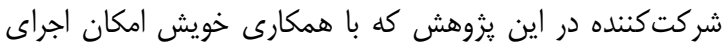
يزروهش را فراهم ساختند، اعلام مىنمايند.

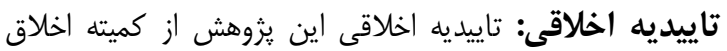

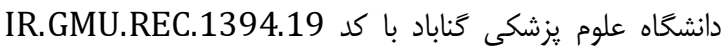

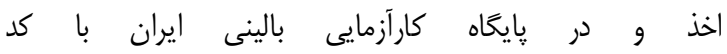
IRCT2015070623103N1 تعارض منافع: هيج كَونه تعارض منافع توسط نويسندكان بيان نشده است. منابع مالى: اين مقاله حاصل بإيانامه دانشجويى مقطع كارشناسىارشد يرستارى در دانشخاه علوم يزشكى گَناباد است.

\section{منابع}

1- Marlow D. Pediatric nursing. Tehran: Boshra Pub; 2009. p. 25. [Persian]

2- Harkreader HR. Fundamentals of nursing. $4^{\text {th }}$ edition. Philadelphia: Saunders Co; 2008. p. 104.

3- Alavi A, Zargham A, Abd Yazdan Z, Namnabati M. Comparison of distraction effects and cream (EMLA) on pain intensity catheter insertion in children 5-12 thalassemia. J Shahrekord Univ Med Sci. 2005;7(3):9-15. [Persian]

4- Vosoghi N, Chehrzad M, Abotalebi Gh, Atrkar Roshan Z. Effects of distraction on physiologic indices and pain

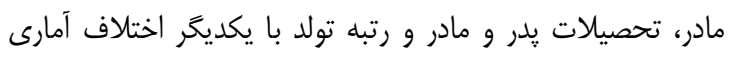

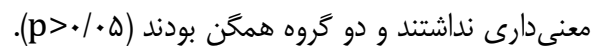

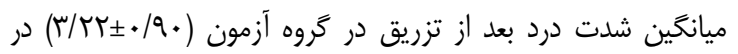

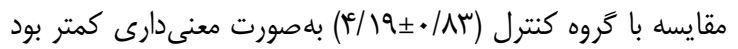
.$(p<+/ . \cdot 1)$

\section{بحث}

در يروهش حاضر تاثير انحراف فكر نمايش تزريق روى عروسك بر بر بردي

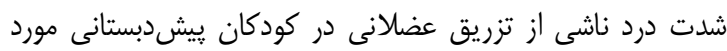

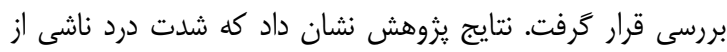

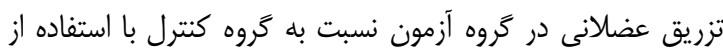
تكنيك انحراف فكر نمايش تزريق روى عروسك كاهش أنس معنى دارى داشت. انحراف فكر يكى از شيوههاى تسكين درد است كه بهدليل تداخل

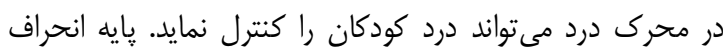

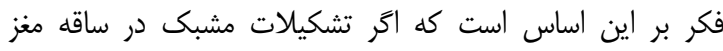

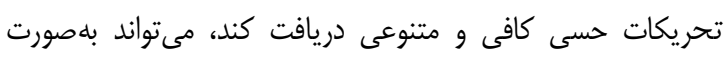

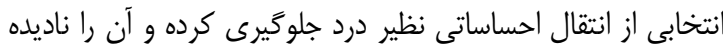

$$
\text { بخيرد [18]. }
$$

مطالعاتى در مورد تاثير روشهاى مختلف انحراف فكر بر كاهش

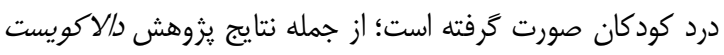
و همكاران نشان داد كه روشهاى مختلف انحراف فكر بلهطور

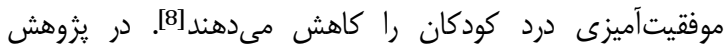

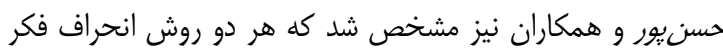

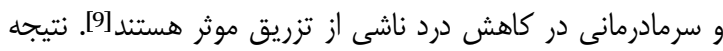

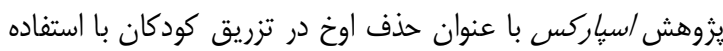

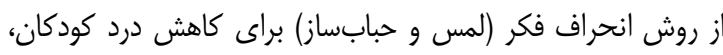

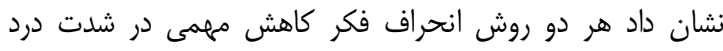

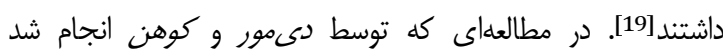

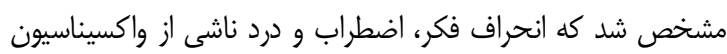

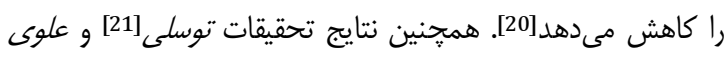



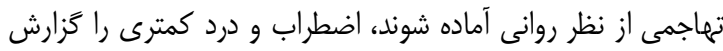





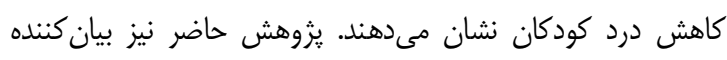
اثربخشى روش تزريق روى عروسك در كاهش شدت درد درد كودكان نيان

$$
\text { ييش دبستانى بوده است. }
$$

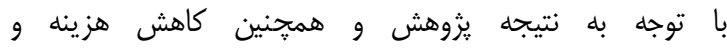

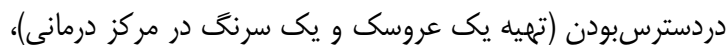

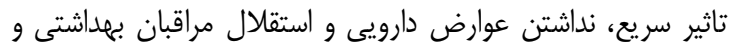



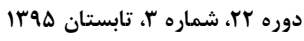
فصلنامه افق دانش 
تاثير نمايش تزريق روى عروسك بر شدت درد ناشى از تزريق عضلانى در كودكان ييشدبستانى

knowledge, attitudes, and self-efficacy of children's pain management: Evaluation of an education program in Taiwan. J Pain Symptom Manage. 2006;32(1):82-9.

14- Valizade F. Comparison two different methods of distraction, using music and breathing techniques HeyHo on pain due to catheter insertion in 12-6 years old children [Dissertation]. Tehran: Shahid Beheshti University of Medical Sciences; 2000. [Persian]

15- Tanabe P, Ferket K, Thomas R, Paice J, Marcantonio $\mathrm{R}$. The effect of standard care, ibuprofen, and distraction on pain relief and patient satisfaction in children with musculoskeletal trauma. J Emerg Nurs. 2002;28(2):11825.

16- Beyer JE, Turner SB, Jones L, Young L, Onikul R, Bohaty $B$. The alternate forms reliability of the oucher pain scale. Pain Manag Nurs. 2005;6(1):10-7.

17- Mehdipor Raberi R, Neematollahi M, Esmaielzadeh Novqaby P. Effect of distraction techniques on pain intensity catheter insertion in children with strabismus. Sci J Hamadan Nurs Midwifery Fac. 2010;18(1):18-28. [Persian]

18- MacLaren JE, Cohen LL. A comparison of distraction strategies for venipuncture distress in children. J Pediatr Psychol. 2005;30(5):387-96.

19- Sparkes L. Taking the "ouch" out of injections for children: Using distraction to decrease pain. Am J Matern Child Nurs. 2001;26(2):72-8.

20- DeMore M, Cohen LL. Distraction for pediatric immunization pain: A critical review. J Clin Psychol Med Setting. 2005;12(4):281-91.

21- Tavasoli HS. Comparison of effect of orientation programs play fast, think on pain and anxiety, injection proceduresand parental satisfaction in children before school age thalassemia Gilan [Dissertation]. Tehran: Tarbiat Modarres University of Medical Sciences; 2008. [Persian]
Intensity in children aged 3-6 undergoing IV injection. Hayat. 2010;16(3\&4):39-47. [Persian]

5- McCarthy AM, Kleiber C. A conceptual model of factors influencing children's responses to a painful procedure when parents are distraction coaches. J Pediatr Nurs. 2006;21(2):88-98.

6- Alavi A, Namnabati M, Abdeyzadeh Z, Parvin N, Akbari $\mathrm{N}$, Samipoor $\mathrm{V}$, et al. Pediatric pain management by nurses in educational hospitals of Shahrekord in 2006. J Shahrekord Univ Med Scie. 2008;10(2):66-71. [Persian]

7- Hadadi Moghadam H, Kheirkhah M, Jamshidi Manesh M, Haghani H. The impact of Distraction Technique on Reducing the Infant's Pain due to Immunization Horizon Med Sci. 2011;16(4):20-7. [Persian]

8- Dahlquist LM, Busby SM, Slifer KJ, Tucker CL, Eischen $\mathrm{S}$, Hilley L, et al. Distraction for children of different ages who undergo repeated needle sticks. J Pediatr Oncol Nurs. 2002;19(1):22-34.

9- Hasanpour M, Tootoonchi M, Aein F, YadegafarG. The effect of two non-pharmacologic pain management methods for intramuscular injectionpain in children. Acute Pain. 2006;8(1):7-12.

10- Taylor C, Lillis C, LeMone P, Lynn P. Fundamentals of nursing: The art and science of nursing care. $7^{\text {th }}$ edition. Philadelphia: Lippincott Williams \& Wilkins; 2010.

11- Asgharinekah SM. Evaluation of potential use in the treatment and rehabilitation of hand dolls autistic children. Tehran: The Secend National Congress of Art Therapy in Iran; 2009. p. 77.

12- Reyhani T, Dehghan Z, Shojaeian R, Asgharinekah SM, Behnam Vashani H. The influence of the puppet Kolah Ghermezi on preoperative anxiety among hospitalized children with appendicitis in Dr Shaikh hospital of Mashhad. J Evid Based Care. 2014;4 (3):77-86. [Persian] 13- Chiang LC, Chen HJ, Huang L. Student nurses' 